\title{
New insights from Thailand into the maternal genetic history of Mainland Southeast Asia
}

\author{
Wibhu Kutanan ${ }^{1,2}$ - Jatupol Kampuansai ${ }^{3,4}$ - Andrea Brunelli $i^{5}$ Silvia Ghirotto ${ }^{5}$ Pittayawat Pittayaporn ${ }^{6}$. \\ Sukhum Ruangchai ${ }^{7} \cdot$ Roland Schröder $^{2} \cdot$ Enrico Macholdt $\mathbb{D}^{2} \cdot$ Metawee Srikummool $^{8} \cdot$ Daoroong Kangwanpong $^{3}$. \\ Alexander Hübner $\mathbb{( \mathbb { D }}^{2} \cdot$ Leonardo Arias $\mathbb{1}^{2} \cdot$ Mark Stoneking $^{2}$
}

Received: 24 July 2017 / Revised: 17 January 2018 / Accepted: 23 January 2018 / Published online: 26 February 2018

(c) The Author(s) 2018. This article is published with open access

\begin{abstract}
Tai-Kadai (TK) is one of the major language families in Mainland Southeast Asia (MSEA), with a concentration in the area of Thailand and Laos. Our previous study of $1234 \mathrm{mtDNA}$ genome sequences supported a demic diffusion scenario in the spread of TK languages from southern China to Laos as well as northern and northeastern Thailand. Here we add an additional 560 mtDNA genomes from 22 groups, with a focus on the TK-speaking central Thai people and the Sino-Tibetan speaking Karen. We find extensive diversity, including 62 haplogroups not reported previously from this region. Demic diffusion is still a preferable scenario for central Thais, emphasizing the expansion of TK people through MSEA, although there is also some support for gene flow between central Thai and native Austroasiatic speaking Mon and Khmer. We also tested competing models concerning the genetic relationships of groups from the major MSEA languages, and found support for an ancestral relationship of TK and Austronesian-speaking groups.
\end{abstract}

Electronic supplementary material The online version of this article (https://doi.org/10.1038/s41431-018-0113-7) contains supplementary material, which is available to authorized users.

Wibhu Kutanan

wibhu@kku.ac.th

$\triangle$ Mark Stoneking

stoneking@eva.mpg.de

1 Department of Biology, Faculty of Science, Khon Kaen University, Khon Kaen, Thailand

2 Department of Evolutionary Genetics, Max Planck Institute for Evolutionary Anthropology, Leipzig, Germany

3 Department of Biology, Faculty of Science, Chiang Mai University, Chiang Mai, Thailand

4 Center of Excellence in Bioresources for Agriculture, Industry and Medicine, Chiang Mai University, Chiang Mai, Thailand

5 Department of Life Science and Biotechnology, University of Ferrara, Ferrara, Italy

6 Department of Linguistics, Faculty of Arts, Chulalongkorn University, Bangkok, Thailand

7 Material Science and Nanotechnology Program, Faculty of Science, Khon Kaen University, Khon Kaen, Thailand

8 Department of Biochemistry, Faculty of Medical Science, Naresuan University, Phitsanulok, Thailand

\section{Introduction}

The geography of Thailand encompasses both upland and lowland areas, and Thailand is one of the most ethnolinguistically-diverse countries in Mainland Southeast Asia (MSEA). With a census size of $\sim 68$ million in 2015, there are 70 different recognized languages belonging to five different major language families: Tai-Kadai (TK) (90.5\%), Austroasiatic (AA) (4.0\%), Sino-Tibetan (ST) (3.2\%), Austronesian (AN) (2.0\%), and Hmong-Mien (HM) $(0.3 \%)$ [1]. The majority of the people $(29.72 \%)$ are called Thai or Siamese and speak a central Thai (CT) language that belongs to the TK family. Since it is the country's official language, the number of people speaking the CT language as their primary or secondary language is $\sim 40$ million [1], or $\sim 68 \%$ of the population.

The recorded history of the CT people or Siamese started with the Sukhothai Kingdom, around the 13th century A.D [2]. However, before the rise of the TK civilization, Thailand was under the control of Mon and Khmer people [3, 4]. Linguistic and archaeological evidence suggests that the prehistorical TK homeland was situated in the area of southeastern or southern China, and that they then spread southward to MSEA around 1-2 kya [5, 6]. This process could have occurred via demic diffusion (i.e., a migration of 
people from southern China, who are then the ancestors of present-day CT people), cultural diffusion (i.e., the CT ancestors were AA groups who shifted to TK languages), or continuous migration (i.e., gene flow between people from southern China and resident AA groups, so CT people have ancestry from both sources). We previously used demographic modeling to test these scenarios, using a large dataset of complete mtDNA genome sequences from Thai/ Lao people, mostly from northern and northeastern Thailand, and found support for the demic diffusion model [7]. However, CT groups were not included in that study, and could have a different history.

Here we extend our previous study by adding 560 new complete mtDNA genome sequences from 22 groups (mostly from CT) speaking TK, AA, and ST languages; when combined with the previous data [7], there are a total of 1794 sequences from 73 Thai/Lao groups. We find extensive diversity in the new groups, including 62 haplogroups not found in the previous study. We use demographic modeling to test three competing scenarios (demic diffusion, cultural diffusion, and continuous migration) for the origins of CT groups. We also use demographic modeling to test competing scenarios for the genetic relationships of groups speaking languages from the major MSEA language families (TK, AA, ST, and AN) [8-11]. Our results provide new insights into the maternal genetic history of MSEA populations.

\section{Materials and methods}

\section{Samples}

Samples were analyzed from 560 individuals belonging to 22 populations classified into four groups: (1) the central Thais (CT) (seven populations: CT1-CT7); (2) the Mon (two populations: MO6-MO7); (3) the TK speaking groups from northern Thailand, including Yuan (four populations: YU3-YU6), Lue (four populations: LU1-LU4) and Khuen (TKH); and (4) the ST speaking Karen (four populations: KSK1, KSK2, KPW and KPA) (Table 1 and Fig. 1). Genomic DNA samples of MO6, Yuan, Lue, Khuen and Karen were from previous studies [12, 13] while the MO7 and CT groups were newly-collected saliva samples obtained with written informed consent. DNA was extracted by QIAamp DNA Midi Kit (Qiagen, Germany). This research was approved by Khon Kaen University, Chiang Mai University, Naresuan University, and the Ethics Commission of the University of Leipzig Medical Faculty.

\section{Sequencing}

We generated complete mtDNA sequences from genomic libraries with double indices and mtDNA enrichment based on protocols described previously [14, 15]. The libraries were sequenced on the Illumina Hiseq 2500. MtDNA consensus sequences were obtained as described by AriasAlvis et al. [16]. except that Illumina standard base calling was performed using Bustard and the read length was $76 \mathrm{bp}$. Sequences were manually checked with Bioedit (www. mbio.ncsu.edu/BioEdit/bioedit.html). A multiple sequence alignment of the sequences and the Reconstructed Sapiens Reference Sequence (RSRS) [17] was obtained by MAFFT 7.271 [18]. The $560 \mathrm{mtDNA}$ genomic sequences reported in this study have been deposited in NCBI GenBank under accession numbers MG272576-MG273135.

\section{Statistical analyses}

Haplogroup assignment was performed with the online tools Haplogrep [19] and MitoTool [20]. Arlequin 3.5.1.3 was used to obtain summary statistics [21]. For the population comparisons, we included an additional $1234 \mathrm{mtDNA}$ genomes from 51 Thai/Lao populations from our previous study [7] (Supplementary Table S1), for a total of 1794 sequences from 73 populations (Fig. 1). The matrix of genetic distances $\left(\Phi_{\mathrm{st}}\right.$, pairwise difference), permutation test, analyses of molecular variance (AMOVA), and a Mantel test of the correlation between genetic and geographic distances were also carried out with Arlequin [21]. Three types of geographic distances were computed, as previously described [7]. To get a broad picture of population relationships in Asia, we included 1936 published mtDNA genomes from 61 Asian populations (Supplementary Table S1) and calculated the $\Phi_{\text {st }}$ matrix by Arlequin [21].

The $\Phi_{\text {st }}$ distance matrix was visualized by a multidimensional scaling plot (MDS) using STATISTICA 10.0 (StatSoft, Inc., USA). A Discriminant Analysis of Principal Components (DAPC) was employed using the dapc function within the adegenet $\mathrm{R}$ package [22]. Median-joining networks [23] of haplogroups without pre-processing and post-processing steps were constructed with Network (www.fluxus-engineering.com) and visualized in Network publisher 1.3.0.0.

Bayesian skyline plots (BSP) per population and maximum clade credibility (MCC) trees per haplogroup, based on Bayesian Markov Chain Monte Carlo (MCMC) analyses, were constructed using BEAST 1.8.0 [24]. BEAST input files were created with BEAUTi v1.8.0 after first running jModel test 2.1.7 in order to choose the most suitable model of sequence evolution [25]. BSP calculations per population and the BEAST runs by haplogroup were executed with respective mutation rates of $1.708 \times 10^{-8}$ and $9.883 \times 10^{-8}$ for data partitioned between coding and noncoding regions [26] and Tracer 1.6 was used to generate the BSP plot from BEAST results. The Bayesian MCMC 


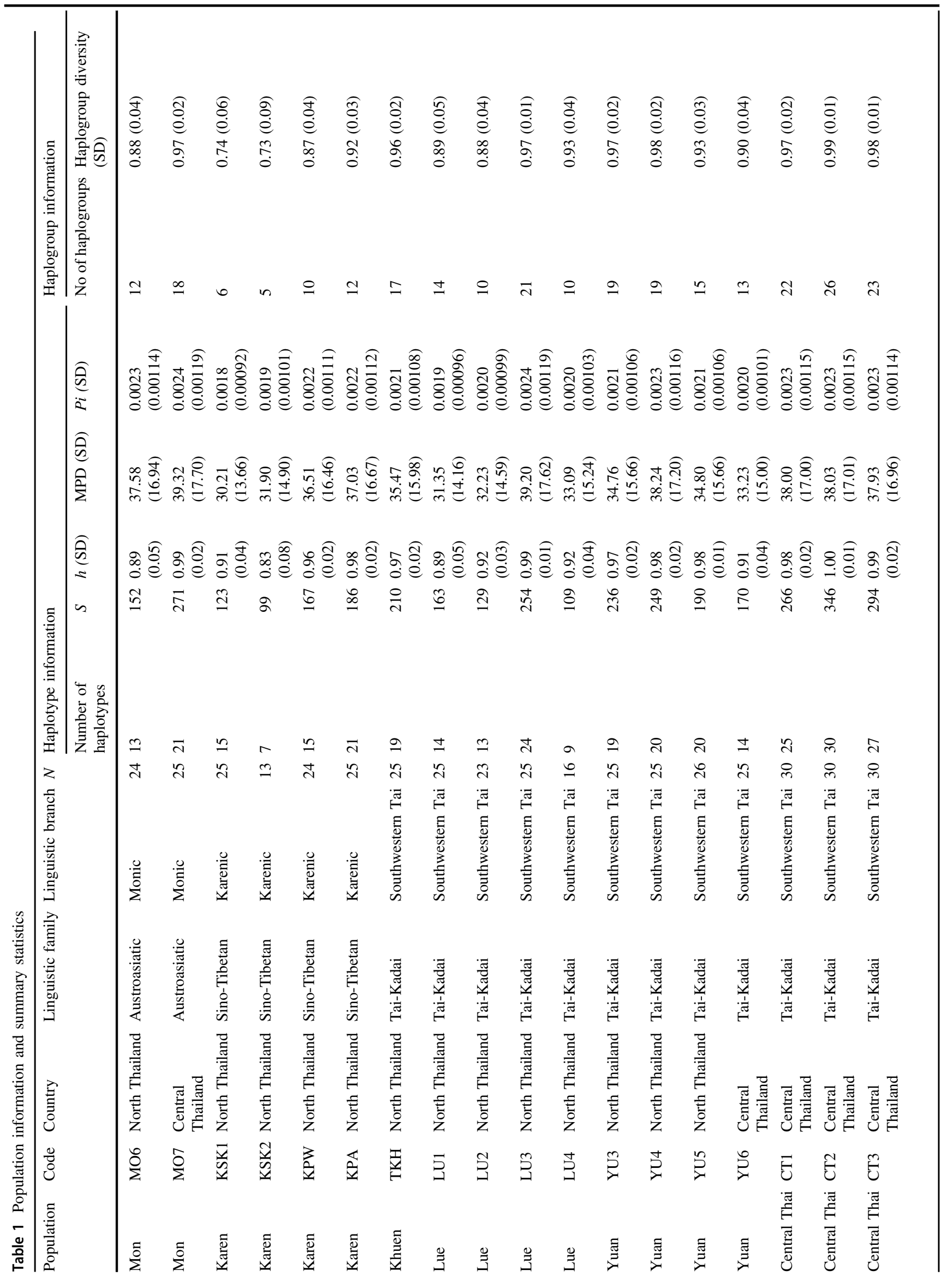




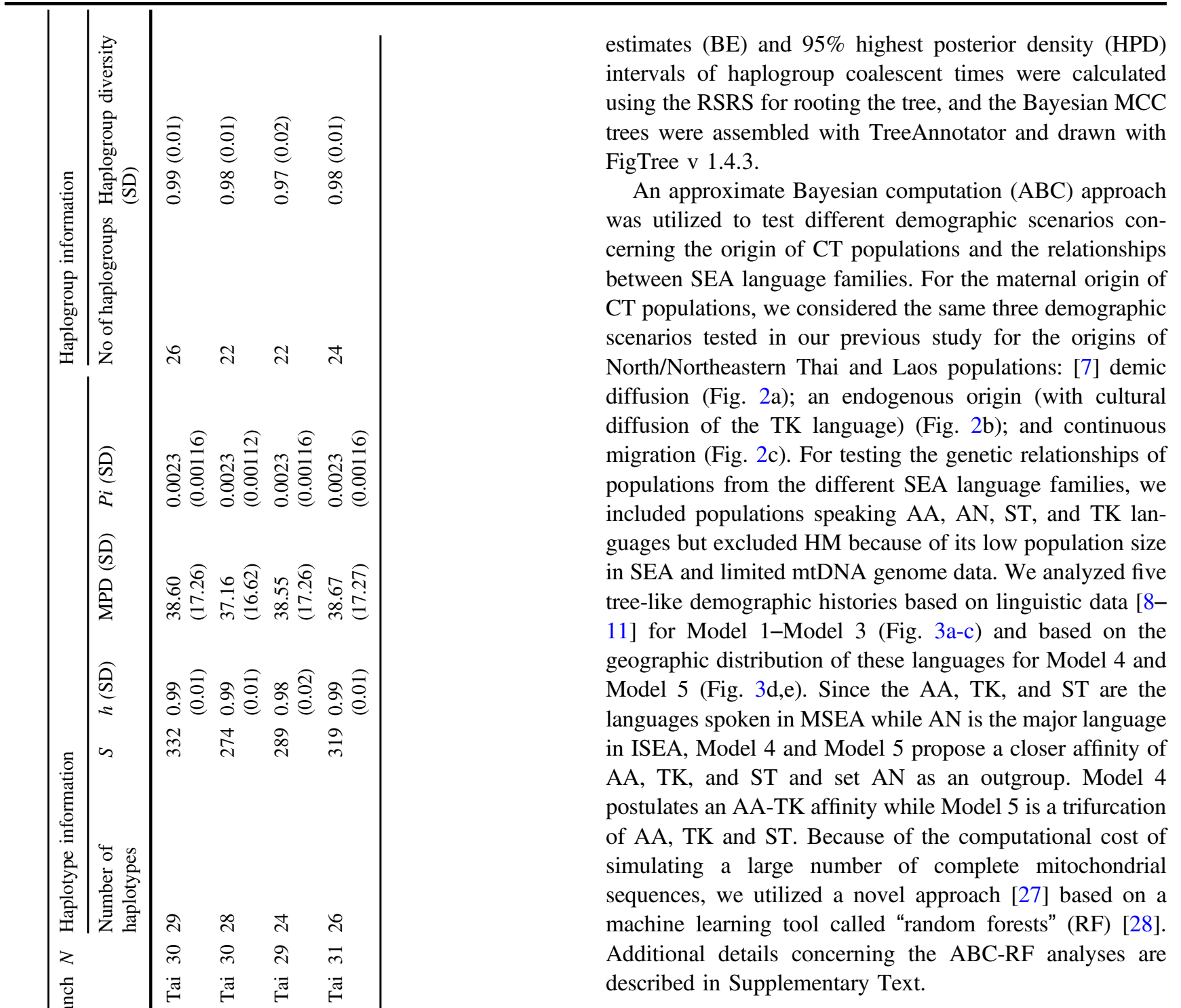

\section{Results}

\section{Genetic diversity and relationships}

We generated 560 complete mtDNA sequences with mean coverages ranging from $54 \times$ to $3687 \times$ and identified 412 haplotypes. Genetic diversity values were lowest in the Karen group KSK2 $(h=0.83 \pm 0.08$; haplogroup diversity $=0.73 \pm 0.09 ; S=99$ ), although this was also the group with the lowest sample size (Table 1). High genetic diversities were observed in CT populations $(h=1.00 \pm 0.01$ in CT2; haplogroup diversity $=0.99 \pm 0.01$ in CT2 and CT4; $S=346$ in CT2) and Mon from central Thailand (MO7) $(\mathrm{MPD}=39.32 \pm 17.70 \quad$ and $\quad \pi=0.0024 \pm 0.00119)$ (Table 1).

We observed 174 haplogroups among the 560 sequences (Supplementary Table S2); when combined with our previous study [7] of Thai/Lao populations, there are a total of 


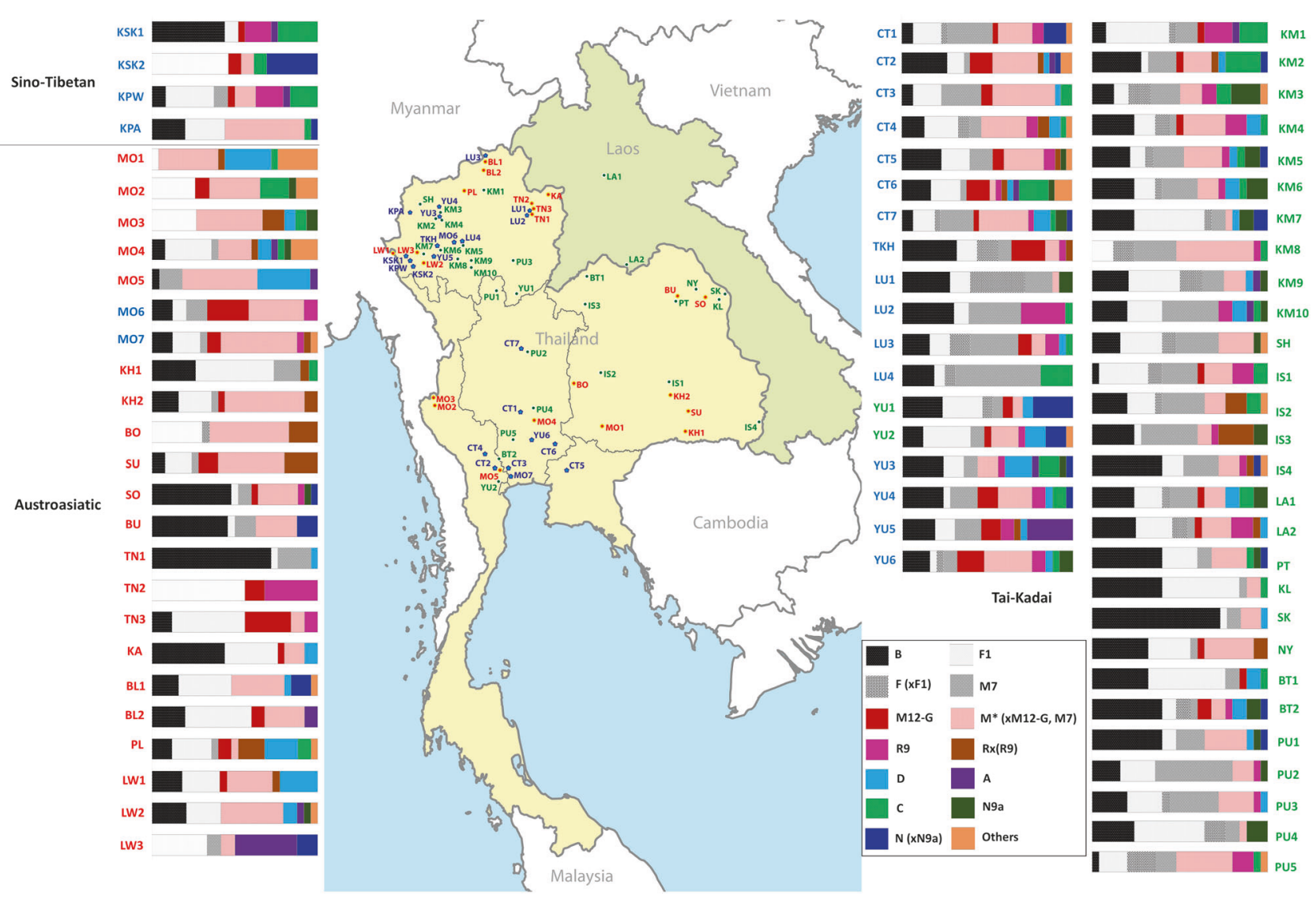

Fig. 1 Map showing sample locations and haplogroup distributions. Blue stars indicate the 22 presently studied populations (Tai-Kadai, Austroasiatic, and Sino-Tibetan groups) while red and green circles represent Tai-Kadai and Austroasiatic populations from the previous study [7]. Population abbreviations are in Supplementary Table S1

(a) Demic diffusion

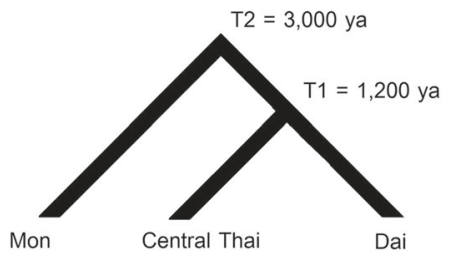

Khmer

(Southern China) (b)

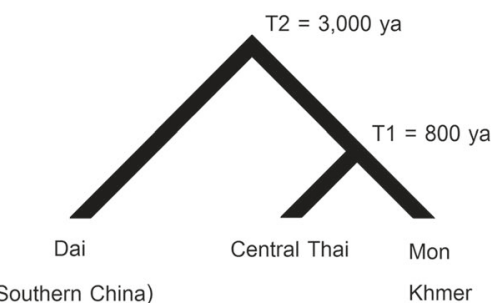

(c)

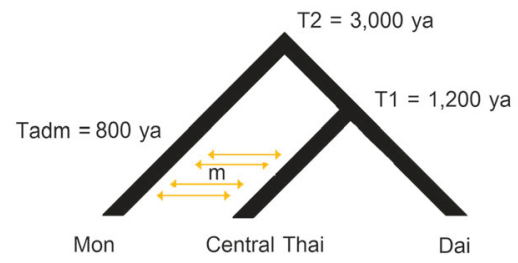

(Southern China)

Fig. 2 Three demographic models for the ABC analysis of CT origins: demic diffusion (a); cultural diffusion (b); and continuous migration (c)

1794 sequences from 73 populations (Fig. 1). In total there are 1103 haplotypes and 274 haplogroups, of which 62 haplogroups were not observed in the previous study [7] (Supplementary Table S3). An analysis of haplotype sharing (Supplementary Figure S1) shows that all four Karen groups (KSK1, KSK2, KPW, and KPA) share haplotypes, indicating high gene flow among them. The Mon (MO6MO7) shared haplotypes with several other ethnic groups, e.g., Yuan (YU) and Central Thai (CT), whereas most of the CT populations shared haplotypes more often with northeastern Thai than northern Thai groups (Supplementary Figure S1).

The AMOVA revealed that overall, $7.10 \%$ of the genetic variation is among populations (Table 2). Classifying populations by language family resulted in a slightly higher proportion of variation among groups $(0.91 \%, P<0.01)$ than a geographic classification $(0.17 \%, P>0.01)$, indicating that language family seems to be a better indicator than geography of the genetic structure of Thai/Lao populations, however there is much more variation among 
(a)

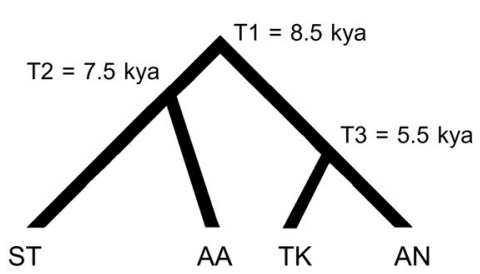

(d)

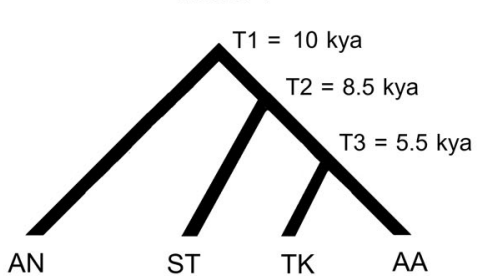

Model 2

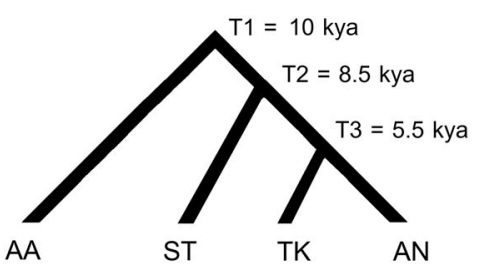

(c)

Model 3

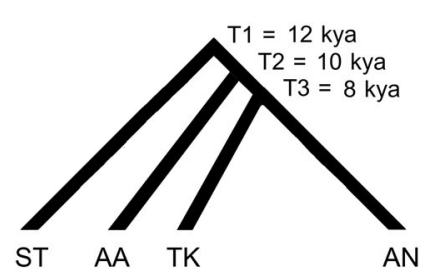

(e)

Model 5

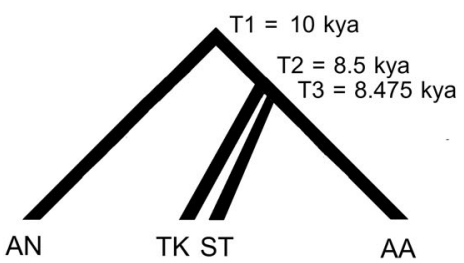

Fig. 3 Five demographic models for the ABC analysis of the relationships of populations from four MSEA language families. Model 1 (a), Model 2 (b), and Model 3 (c) are based on Starosta (2005) [11], Sagart (2004, 2005) [9, 10] and Peiros (1998) [8], respectively, while Model 4 (e) and Model 5 (f) are based on the present geographic distributions of the languages (ISEA for AN and MSEA for ST, TK, and AA); see Supplementary Text for further details

Table 2 AMOVA results

\begin{tabular}{|c|c|c|c|c|c|}
\hline No. of groups & $\begin{array}{l}\text { No. of } \\
\text { groups }\end{array}$ & $\begin{array}{l}\text { No. of } \\
\text { populations }\end{array}$ & $\begin{array}{l}\text { Within } \\
\text { populations }\end{array}$ & $\begin{array}{l}\text { Among populations } \\
\text { within groups }\end{array}$ & $\begin{array}{l}\text { Among } \\
\text { groups }\end{array}$ \\
\hline Total $^{\mathrm{a}}$ & 1 & 73 & 92.90 & $7.10 *$ & \\
\hline $\mathrm{AA} / \mathrm{TK} / \mathrm{ST}^{\mathrm{a}}$ & 3 & 73 & $92.47 *$ & $6.62 *$ & $0.91 *$ \\
\hline Austroasiatic $^{\mathrm{a}}$ & 1 & 23 & 88.86 & $11.14 *$ & \\
\hline Mon $^{\mathrm{a}}$ & 1 & 7 & 93.10 & $6.90 *$ & \\
\hline $\mathrm{H}^{\prime} \operatorname{tin}^{\mathrm{b}}$ & 1 & 3 & 74.29 & $25.71 *$ & \\
\hline Lawa $^{\mathrm{b}}$ & 1 & 3 & 92.22 & $7.78^{*}$ & \\
\hline $\begin{array}{l}\text { Sino-Tibetan } \\
\text { (Karen) }\end{array}$ & 1 & 4 & 93.49 & $6.51^{*}$ & \\
\hline Tai-Kadai $^{\text {a }}$ & 1 & 46 & 95.41 & $4.59 *$ & \\
\hline Lue & 1 & 4 & 92.74 & $7.26^{*}$ & \\
\hline Yuan & 1 & 6 & 96.10 & $3.90 *$ & \\
\hline Central Thai & 1 & 7 & 98.36 & $1.64 *$ & \\
\hline Khon Mueang ${ }^{\mathrm{b}}$ & 1 & 10 & 96.57 & $3.43 *$ & \\
\hline Lao Isan ${ }^{\mathrm{b}}$ & 1 & 4 & 97.69 & $2.31 *$ & \\
\hline Phuan $^{\mathrm{b}}$ & 1 & 5 & 94.71 & $5.29 *$ & \\
\hline Geography ${ }^{\mathrm{a}}$ & 6 & 73 & $92.85 *$ & $6.99 *$ & 0.17 \\
\hline Northern ${ }^{\mathrm{a}}$ & 1 & 38 & 92.13 & $7.83 *$ & \\
\hline Northeastern ${ }^{\mathrm{b}}$ & 1 & 16 & 91.29 & $8.71 *$ & \\
\hline Central $^{\mathrm{a}}$ & 1 & 14 & 95.84 & $4.16^{*}$ & \\
\hline Western $^{\mathrm{a}}$ & 1 & 3 & 99.12 & 0.88 & \\
\hline
\end{tabular}

${ }^{*} P<0.01$

${ }^{\text {a }}$ Data combined from present and previous studies [7] to total 73 populations

${ }^{\mathrm{b}}$ Data set from Kutanan et al. [7]

populations within the same group for both classifications (Table 2). Within each language family, the variation among AA groups (11.14\%) was greater than that of ST
$(6.51 \%)$ or TK $(4.59 \%)$ groups, indicating greater genetic heterogeneity of AA groups. Interestingly, we observed that the CT groups are the most homogenous of the TK groups, 
with only $1.64 \%$ of the variation among groups. However, Lue groups had higher heterogeneity $(7.26 \%)$ than the average for TK groups $(4.59 \%)$. A Mantel test for correlations between genetic and geographic distances indicates no correlation for all three types of geographic distances, i.e. great circle distance $(r=0.0216, P>0.01)$, resistance distance $(r=-0.0996, P>0.01)$ and least-cost path distance $(r=0.0459, \quad P>0.01)$, further supporting the limited impact of geography on the genetic structure of Thai/Lao populations. Furthermore, a DAPC analysis showed that clustering groups by language family resulted in more discrimination among groups than clustering by geographic criteria (Supplementary Figure S2).

The MDS showed that the most differentiated groups were two H'tin groups (TN2 and TN1) and Seak (SK), as found previously [7] and in the central cloud of the plot it is difficult to see population clustering trends (Supplementary Figure S3). Genetic distance values exhibited larger significantly genetic difference of the AA populations than the TK populations, supporting greater genetic divergence of the AA groups (Supplementary Figure S4). After omitting these outlier groups (TN1, TN2, and SK), a 3-dimensional MDS provides an acceptable fit (Fig. 4a-c) and shows some clustering of populations by language family (with considerable overlap). The MDS plot of Asian populations indicated that SEA groups are separated from Indian groups; some Mon groups (MO1, MO5 and MO6) are closely related to the Indian groups as well as Myanmar (BR1 and BR2) and Cambodia (KH_C and AA_C), while the other Mon (MO2-MO4, MO7) are close to the other SEA populations (Supplementary Figure S5).

\section{MtDNA haplogroups}

Fourteen of the 174 haplogroups occur in at least ten individuals and together account for $33.92 \%$ of the 560 sequences; these are F1a1a, B6a1a, F1f, B5a1a, F1a1a1, C7a1, C7a, M*, M12a1a, M21a, M7b1a1a3, R9b1a1a, R9b1a3, and B5a1b1 (Supplementary Table S3). These common haplogroups are mostly prevalent in AA groups (e.g., $\mathrm{M}^{*}$ and M12a1a in MO6, 50.00\%) and STspeaking Karen groups (B6a1a, C7a1, R9b1a1a in KSK1, 84.00\%; F1a1a in KSK2, 46.15\%; F1a1a, C7a1, R9b1a1a in KPW, 70.83\%; B6a1a, F1a1a1, M*, and M21a in KPA, $56.00 \%$ ). These very distinct haplogroup distributions further emphasize the genetic distinctiveness of AA and ST groups.

The remaining haplogroups $(66.08 \%)$, which occur in lower frequency, tend to be more widely distributed, e.g., G2a1 and basal M sublineages in MO7 and subhaplogroups F (x F1a1a and F1a1a1), M7b1a1 and B4 in Lue (LU) and Khuen (TKH) at varying frequencies (Supplementary Table S3). New subhaplogroups of B4 (B4a1a, B4a1c2,
B4b1c1, B4c, B4c2c, B4g2, and B4m), F3 (F3a, F3b, F3b + 152) and M7 (M7b1a1g, M7b1a1h, M7c1c3, and M7c2b) are present mostly in TK populations (Supplementary Table S3). In agreement with the AMOVA results (Table 2), the CT groups were more similar in haplogroup distribution. The CT groups show a wide haplogroup distribution with various haplogroups occurring in a few individuals and very few haplogroups at high frequency (most are lower than 10\%). Several subclades of $\mathrm{M}$ lineages (M12a2, M12b2, M13b1, M17c1a1, M17c1a1a, M21b2, M2a1a, M32'56, M37e2, M50a1, M51a1a, M73a1, M73b, M7, M7b, M7b1a1g, M7c1c3, and M7c2b) are newlyreported in Thai/Lao groups and are exclusively found in CT populations. Interestingly, other new haplogroups, e.g., R11'B6, R21, R23, U1a1c1a, U1a1c1d, U2a1b, and U2a2 were also observed in the CT groups (Supplementary Table S3).

In the combined Thai/Lao dataset, SEA specific haplogroups (B, F, and M7) are prevalent in almost all groups (overall frequency 55.18\%), with the exception of some AA groups (i.e., Mon, Suay, Nyahkur, Khmer, and Lawa), Karen, and CT groups; these groups have other widespread haplogroups, e.g., D, M12-G, M (xM12-G, M7), A, C, and $\mathrm{N}$ (xN9a) (Fig. 1). Networks of common SEA specific haplogroups, e.g., B5a, F1a, F1f, and M7b, tend to exhibit star-like structures, indicative of population expansions (Supplementary Figure S6). Apart from F1a1a (xF1a1a1), other more-prevalent haplogroups of Karen (B6a1a and C7a1) do not show indications of population expansion, but rather sharing of sequences, suggesting population contraction (Supplementary Figure S6). Apart from B and F1, other lineages, that is, $\mathrm{C} 7 \mathrm{a} 1$ and $\mathrm{A} 17$ and $\mathrm{N} 8$ which are sublineages of $\mathrm{C}, \mathrm{A}$, and $\mathrm{N}$ (xN9a), respectively are observed in the Karen (Fig. 1). Haplogroup C7 has a very high frequency in northeast Asia and eastern India [29] while haplogroup A was previously reported to be specific to North and Central Asia [30]. A high proportion of C and A lineages were previously observed in ST-speaking Barmar and Karen from Myanmar [31]. For the TK-specific haplogroups, i.e. B4 and M7c, there was no obvious signal of population expansion in the networks (Supplementary Figure S6).

For the combined dataset, we estimated coalescence ages of SEA haplogroups and their sublineages. We analyzed haplogroups that have additional sequences from the present study and have more than five sequences in total (Table 3). The ages of major haplogroups are generally consistent with previous studies [7]. However, we obtained more data from several sublineages which were not dated previously, e.g., B4c1b, B6a1, C4, C7a, D4a, F1c, F1e, F1g, F2, F3, F4a2, and G2a (Table 3).

There are many lineages with ages older than $30 \mathrm{kya}$ found in our Thai/Lao samples, e.g. B4, B5, D, F1, F3, M7, 
Fig. 4 MDS plots based on the $\Phi_{\text {st }}$ distance matrix for 70 populations (after removal of three outliers: TN1, TN2, and SK). Red, black, and dark blue symbols indicate AA, TK, and ST populations, respectively. The stress value is 0.0804 . Population abbreviations are shown in Supplementary Table S1
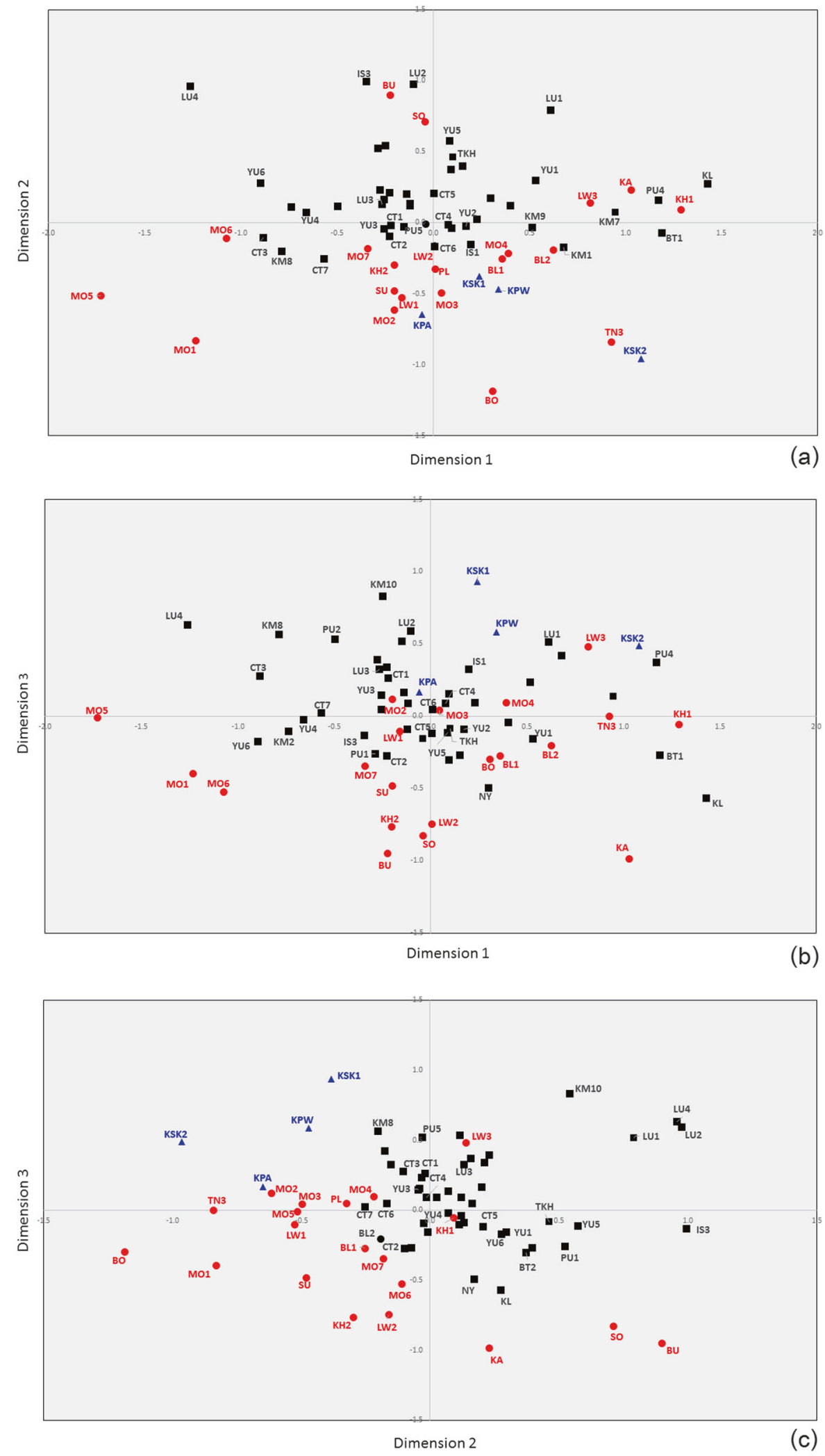

M*, M12, M13, M17, M21, M71, M73, M74, M91, R9, R22, N10, and U (Table 3). Many of them are major lineages and distributed in our Thai/Lao samples as well as in other SEA populations, and have been previously discussed [7]. Here, we focused on some uncommon ancient lineages, i.e., $\mathrm{M}^{*}$, M17, M21, M71, M73, M91 and U; these 
Table 3 Coalescent ages based on Bayesian estimation with 95\% highest posterior density (HPD) interval and using the 1794 Thai/Lao mtDNA sequences

\begin{tabular}{|c|c|c|c|c|}
\hline Haplogroup & Sample size & Age & Lower HPD & Upper HPD \\
\hline A & 29 & $26,727.62$ & $19,134.96$ & $34,370.35$ \\
\hline A17 & 18 & $14,718.80$ & 9621.01 & $20,111.49$ \\
\hline B4 & 111 & $38,117.19$ & $30,932.00$ & $45,747.00$ \\
\hline B4a & 24 & $18,917.86$ & $12,195.35$ & $26,000.54$ \\
\hline B4a1c & 19 & $14,040.58$ & 8999.92 & $19,528.39$ \\
\hline B4a1c4 & 17 & 9528.46 & 5673.92 & $13,668.78$ \\
\hline $\mathrm{B} 4 \mathrm{~b}$ & 28 & $24,710.85$ & $16,441.00$ & $33,801.00$ \\
\hline B $4 b 1 a 2 a$ & 24 & $15,321.55$ & 9733.91 & $20,731.42$ \\
\hline $\mathrm{B} 4 \mathrm{c}$ & 31 & $30,431.00$ & $21,942.00$ & $39,431.00$ \\
\hline $\mathrm{B} 4 \mathrm{c} 2$ & 18 & $12,761.47$ & 7702.42 & $18,226.73$ \\
\hline $\mathrm{B} 4 \mathrm{c} 1 \mathrm{~b}$ & 12 & $19,240.12$ & $13,310.49$ & $25,478.94$ \\
\hline $\mathrm{B} 4 \mathrm{c} 1 \mathrm{~b} 2 \mathrm{a}$ & 8 & 6138.65 & 2610.16 & $10,246.61$ \\
\hline $\mathrm{B} 4 \mathrm{e}$ & 7 & $18,858.29$ & $11,944.27$ & $26,176.60$ \\
\hline B $4 \mathrm{~g}$ & 16 & $20,907.02$ & $14,668.34$ & $27,536.96$ \\
\hline $\mathrm{B} 4 \mathrm{~g} 1 \mathrm{a}$ & 9 & $14,489.99$ & 8675.18 & $20,344.45$ \\
\hline B5 & 201 & $36,842.00$ & $25,885.72$ & $48,319.25$ \\
\hline B5a & 199 & $23,148.45$ & $16,360.26$ & $30,563.55$ \\
\hline B5a1a & 84 & $10,528.38$ & 7009.64 & $14,495.93$ \\
\hline B5a1b1 & 36 & $13,822.52$ & 8588.07 & $20,104.00$ \\
\hline B5a1d & 56 & $11,062.58$ & 6131.41 & $16,415.04$ \\
\hline B6 & 63 & $26,393.00$ & $17,899.18$ & $35,489.50$ \\
\hline B6a & 62 & $26,070.00$ & $17,489.66$ & $37,976.56$ \\
\hline B6a1 & 30 & $14,238.58$ & 9056.86 & $20,278.34$ \\
\hline B6a1a & 25 & 7767.77 & 4262.58 & $11,673.23$ \\
\hline $\mathrm{C}$ & 68 & $25,440.22$ & $17,812.10$ & $33,715.36$ \\
\hline $\mathrm{C} 4$ & 5 & $15,623.14$ & 9466.73 & $22,086.5$ \\
\hline $\mathrm{C} 7$ & 63 & $17,656.94$ & $12,358.50$ & $23,271.62$ \\
\hline $\mathrm{C} 7 \mathrm{a}$ & 54 & $13,603.14$ & 9194.84 & $18,382.15$ \\
\hline C7a1 & 23 & $10,367.90$ & 6654.91 & $14,597.69$ \\
\hline $\mathrm{C} 7 \mathrm{a} 2$ & 12 & $10,386.35$ & 6153.21 & $14,742.98$ \\
\hline $\mathrm{D}$ & 74 & $36,798.49$ & $27,898.26$ & $46,589.35$ \\
\hline D4 & 64 & $25,798.50$ & $20,509.37$ & $31,783.61$ \\
\hline $\mathrm{D} 4 \mathrm{a}$ & 9 & 9859.99 & 5376.12 & $14,845.92$ \\
\hline $\mathrm{D} 4 \mathrm{e}$ & 12 & $17,624.07$ & $11,995.21$ & $23,539.76$ \\
\hline D4e1a & 9 & 9745.70 & 4560.27 & $12,559.22$ \\
\hline D4g2a1 & 9 & $10,492.59$ & 6241.66 & $15,288.36$ \\
\hline $\mathrm{D} 4 \mathrm{~h}$ & 5 & $16,952.97$ & $10,817.29$ & $23,104.15$ \\
\hline $\mathrm{D} 4 \mathrm{j}$ & 17 & $18,371.55$ & $12,999.08$ & $24,001.54$ \\
\hline D4j1 & 13 & $15,823.95$ & $10,608.52$ & $21,007.27$ \\
\hline D4j1a1 & 9 & 6358.27 & 2908.62 & 9832.51 \\
\hline D5 & 10 & $25,766.14$ & $18,288.75$ & $33,469.45$ \\
\hline D5b & 9 & $16,030.28$ & $10,117.31$ & $21,638.32$ \\
\hline $\mathrm{F} 1$ & 348 & $32,264.31$ & $24,186.28$ & $41,022.47$ \\
\hline F1a & 233 & $17,597.91$ & $12,944.06$ & $23,163.01$ \\
\hline F1a1a & 173 & $12,638.86$ & 8885.19 & $17,132.37$ \\
\hline
\end{tabular}

Table 3 (continued)

\begin{tabular}{|c|c|c|c|c|}
\hline Haplogroup & Sample size & Age & Lower HPD & Upper HPD \\
\hline F1a1a1 & 85 & $10,369.11$ & 7590.21 & $11,810.60$ \\
\hline $\begin{array}{l}\text { F1a1a } \\
\text { (xF1a1a1) }\end{array}$ & 88 & $11,109.26$ & 7478.32 & $12,625.46$ \\
\hline F1a1d & 18 & 6483.33 & 2907.29 & $10,528.77$ \\
\hline F1a2 & 9 & 2567.61 & 1266.12 & 4004.97 \\
\hline F1a3 & 17 & 10843.88 & 5123.02 & 17179.15 \\
\hline F1c & 6 & $11,469.20$ & 5757.86 & $17,714.81$ \\
\hline F1e & 7 & $19,513.31$ & $13,131.04$ & $26,560.48$ \\
\hline F1f & 84 & $10,980.60$ & 7235.09 & $15,626.73$ \\
\hline F1g & 7 & 7927.03 & 3268.77 & $13,610.44$ \\
\hline $\mathrm{F} 2$ & 21 & $23,935.18$ & $17,170.83$ & $31,353.49$ \\
\hline $\mathrm{F} 2 \mathrm{~b} 1$ & 10 & $12,369.01$ & 7203.14 & $17,946.33$ \\
\hline F3 & 24 & $34,837.55$ & $25,447.52$ & $44,537.38$ \\
\hline F3a & 21 & $28,288.93$ & $19,595.19$ & $36,229.15$ \\
\hline F3a1 & 20 & $19,112.58$ & $12,812.29$ & $25,873.93$ \\
\hline $\mathrm{F} 4 \mathrm{a} 2$ & 8 & $15,044.48$ & 7932.17 & $23,167.29$ \\
\hline $\mathrm{G}$ & 29 & $29,188.81$ & $21,216.46$ & $37,267.34$ \\
\hline $\mathrm{G} 2$ & 27 & $23,548.73$ & $17,390.75$ & $30,030.55$ \\
\hline $\mathrm{G} 2 \mathrm{a}$ & 13 & $14,109.08$ & 9224.14 & $19,142.22$ \\
\hline G2a1d2 & 5 & 5799.32 & 2348.73 & 9274.34 \\
\hline G2a1 & 13 & $14,109.08$ & 9224.14 & $19,142.22$ \\
\hline G2b1a & 11 & $11,690.98$ & 6270.33 & $17,467.79$ \\
\hline $\mathrm{M}^{*}$ & 19 & $54,274.26$ & $43,577.11$ & $66,359.72$ \\
\hline M5 & 10 & $36,678.71$ & $27,214.35$ & $46,072.13$ \\
\hline M7 & 212 & $41,391.12$ & $31,837.71$ & $50,939.56$ \\
\hline M7b & 171 & $35,034.44$ & $26,840.83$ & $43,472.38$ \\
\hline M7b1a1 & 167 & $15,990.67$ & $12,303.53$ & $19,874.86$ \\
\hline $\begin{array}{l}\text { M7b1a1 } \\
\text { (xothers) }\end{array}$ & 19 & $13,558.17$ & 8123.79 & $19,884.27$ \\
\hline $\begin{array}{l}\text { M7b1a1 } \\
\text { (16192T) }\end{array}$ & 24 & $12,637.55$ & 7673.19 & $17,631.73$ \\
\hline M7b1a1a3 & 38 & $12,584.53$ & 7703.90 & $18,117.30$ \\
\hline M7b1a1b & 25 & $10,445.84$ & 5258.37 & $16,254.46$ \\
\hline M7b1alf & 18 & $13,245.80$ & 7530.63 & $19,433.30$ \\
\hline M7b1a1e & 23 & 7791.66 & 3724.14 & $12,403.34$ \\
\hline M7b1a1d1 & 5 & 2972.49 & 446.41 & 6159.96 \\
\hline M7c & 40 & $30,732.28$ & $22,122.71$ & $39,141.31$ \\
\hline M7c1 & 30 & $21,566.96$ & $14,859.8$ & $28,153.25$ \\
\hline M7c1a & 16 & $17,464.84$ & $10,886.82$ & $22,890.26$ \\
\hline M7c1c & 10 & $10,618.92$ & 5486.60 & $16,461.94$ \\
\hline M7c2 & 10 & 8857.81 & 5156.31 & $13,208.00$ \\
\hline M8a2a1 & 12 & $12,289.16$ & 6303.89 & $19,070.80$ \\
\hline M9 & 13 & $25,048.34$ & $16,817.63$ & $33,645.48$ \\
\hline M12-G & 77 & $49,208.31$ & $38,581.81$ & $60,249.67$ \\
\hline M12 & 48 & $34,273.83$ & $27,438.97$ & $41,570.70$ \\
\hline M12a & 35 & $31,049.21$ & $24,795.78$ & $37,838.12$ \\
\hline M12a1a & 26 & $21,687.96$ & $16,394.10$ & $27,437.19$ \\
\hline
\end{tabular}


Table 3 (continued)

\begin{tabular}{|c|c|c|c|c|}
\hline Haplogroup & Sample size & Age & Lower HPD & Upper HPD \\
\hline M12a1b & 5 & $21,169.00$ & $15,368.51$ & $27,771.39$ \\
\hline M12b1b & 8 & 7482.85 & 3500.09 & $11,993.80$ \\
\hline M12b & 13 & $25,046.13$ & $18,605.47$ & $31,841.06$ \\
\hline M13 & 6 & $50,710.00$ & $37,118.08$ & $64,142.80$ \\
\hline M17 & 18 & $40,904.24$ & $30,197.33$ & $52,184.59$ \\
\hline M17a & 5 & $20,009.10$ & $13,015.45$ & $27,964.05$ \\
\hline M17c & 13 & $32,177.80$ & $23,403.54$ & $41,810.14$ \\
\hline M17c1a & 6 & $17,915.50$ & $12,186.65$ & $24,567.08$ \\
\hline M20 & 30 & $12,477.81$ & 7287.09 & $17,537.99$ \\
\hline M21 & 20 & $42,734.21$ & $33,264.99$ & $53,871.33$ \\
\hline M21a & 7 & 3930.28 & 745.70 & 8746.90 \\
\hline $\mathrm{M} 21 \mathrm{~b}$ & 13 & $34,539.86$ & $27,357.67$ & $42,665.79$ \\
\hline M24 & 23 & $19,997.93$ & $12,330.76$ & $28,223.99$ \\
\hline $\mathrm{M} 24 \mathrm{a}$ & 13 & 9808.57 & 4590.87 & $15,938.40$ \\
\hline $\mathrm{M} 24 \mathrm{~b}$ & 10 & $10,410.36$ & 5535.44 & $15,467.68$ \\
\hline M51 & 13 & $29,132.45$ & $20,474.60$ & $38,980.81$ \\
\hline M51a & 11 & $23,652.72$ & $15,649.38$ & $30,973.61$ \\
\hline M61 & 9 & $12,811.00$ & 5846.11 & $20,533.93$ \\
\hline M71 & 31 & $31,226.61$ & $23,598.07$ & $39,142.13$ \\
\hline M71(151T) & 14 & $23,561.12$ & $17,922.81$ & $29,228.41$ \\
\hline M71a & 12 & $23,996.16$ & $17,978.14$ & $29,850.89$ \\
\hline M71a2 & 7 & $15,377.76$ & 9811.96 & $21,043.64$ \\
\hline M72 & 10 & $15,399.31$ & 8120.81 & $22,767.31$ \\
\hline M73 & 9 & $36,206.88$ & $24,769.66$ & $47,741.06$ \\
\hline M74 & 35 & $34,052.07$ & $25,392.91$ & $42,794.43$ \\
\hline M74a & 6 & 9157.03 & 3700.32 & $14,608.82$ \\
\hline $\mathrm{M} 74 \mathrm{~b}$ & 26 & $24,068.66$ & $18,199.97$ & $30,801.78$ \\
\hline M76 & 12 & $30,665.07$ & $20,459.90$ & $42,014.36$ \\
\hline M91 & 11 & $35,980.00$ & $24,612.34$ & $48,440.13$ \\
\hline M91a & 10 & $15,874.00$ & 9310.13 & $23,117.39$ \\
\hline N8 & 8 & 5670.00 & 1800.20 & $10,274.52$ \\
\hline N9a & 40 & $23,307.91$ & $16,466.89$ & $31,217.48$ \\
\hline N9a6 & 9 & $12,157.84$ & 7080.02 & $17,014.10$ \\
\hline N9a10 & 19 & $15,864.76$ & $11,161.95$ & $20,533.24$ \\
\hline N10 & 12 & $51,144.71$ & $35,516.27$ & $65,932.28$ \\
\hline $\mathrm{N} 10 \mathrm{a}$ & 11 & $11,002.31$ & 6044.77 & $16,435.19$ \\
\hline N21 & 15 & $11,924.14$ & 7327.79 & $17,377.08$ \\
\hline R9 & 75 & $36,737.77$ & $28,196.01$ & $45,770.54$ \\
\hline $\mathrm{R} 9 \mathrm{~b}$ & 68 & $32,837.96$ & $25,372.79$ & $40,740.86$ \\
\hline R9b1 & 48 & $20,294.50$ & $15,024.28$ & $26,305.99$ \\
\hline R9b1a & 42 & $14,387.62$ & 9257.45 & $20,045.40$ \\
\hline R9b1a1a & 12 & 7547.06 & 4217.30 & $11,157.00$ \\
\hline R9b1a3 & 26 & 9062.02 & 5398.62 & $13,213.44$ \\
\hline R9b2 & 18 & 8945.97 & 5003.56 & $13,337.12$ \\
\hline $\mathrm{R} 9 \mathrm{c} 1$ & 7 & $22,854.33$ & $15,036.92$ & $30,754.85$ \\
\hline $\mathrm{R} 22$ & 26 & $39,111.69$ & $30,325.41$ & $49,812.23$ \\
\hline $\mathrm{U}$ & 8 & $52,604.10$ & $41,647.27$ & $63,469.01$ \\
\hline W & 8 & $13,994.04$ & 7354.74 & $21,364.09$ \\
\hline
\end{tabular}

are described in Supplementary Text. Overall, the CT groups contrast with other Thai/Lao groups in exhibiting several ancient haplogroups (in particular basal $\mathrm{M}$ lineages, i.e., M13, M17, M21b, M71, M73, M91a, and U) at low frequency. Notably, M17, M21, M71, and M73 are ancient maternal lineages of SEA found in both MSEA and ISEA, reflecting linkages between the early lineages in SEA [32].

Finally, several haplogroups associated with the AS expansion from Taiwan [33-36], namely B4a1a1a, M7b3, M7c3c, E1a1a, and Y2 were not observed, suggesting that this expansion had at most a limited impact on mtDNA lineages in MSEA.

\section{Bayesian skyline plots}

BSP of population size change over time were constructed for each group, and five typical patterns were observed (Fig. 5). The four Karen populations all showed different patterns: KSK2 (and also MO6 and LU4) displayed unchanged population size until 1-2 kya followed by sharp reductions (Fig. 5, pattern a); KSK1 was also constant in size, with a sudden increase in the last 1-2 kya (Fig. 5, pattern b); KPA was basically constant in size over time (Fig. 5, pattern c); and KPW exhibited the most common pattern (also observed in MO7, KPW, TKH, LU1-LU2, YU3-YU6, CT6-CT7), consisting of population expansion between 50-60 kya, followed by a decrease in the last $5 \mathrm{kya}$ (Fig. 5, pattern d). While recent reductions in population size could reflect recent bottlenecks, such changes during recent times should be interpreted cautiously as they may reflect a bias in sampling [37]. Finally, population growth without further change was found for LU3 and CT1-CT5 (Fig. 5, pattern e). The BSP plots for each individual population are depicted in Supplementary Figure S7.

\section{Demographic models for the origin of central Thai people}

In our previous study we used demographic modeling to show that northern and northeastern Thai groups most likely originated via demic diffusion from southern China [7]. Here we use the same approach to test three demographic scenarios concerning the origins of central Thai groups: (1) descent from the prehistorical Tai stock of southern China via demic diffusion, like their neighbors in the North and Northeast of Thailand (Fig. 2a); (2) local AA groups (Mon and Khmer) who changed their identity and language via cultural diffusion to become TK groups (Fig. 2b); or (3) descent from a migration from southern China that received gene-flow from the local Mon and Khmer people (Fig. 2c). The estimated values of $\mathrm{ABC}-\mathrm{RF}$ prior error rate with respect to the number of trees in the forest indicated that 500 trees were sufficient in our analyses (Supplementary 
Fig. 5 The BSP plots for five different trends found in 22 populations; KSK2, MO6, LU4 (a), KSK1 (b), KPA (c), KPW, MO7, KPW, TKH, LU1-LU2, YU3-YU6, CT6-CT7 (d), and LU3, CT1-CT5 (e). Population abbreviations are listed in Table 1. Each line is the median estimated maternal effective population size (y-axis) through time from the present in years (x-axis)

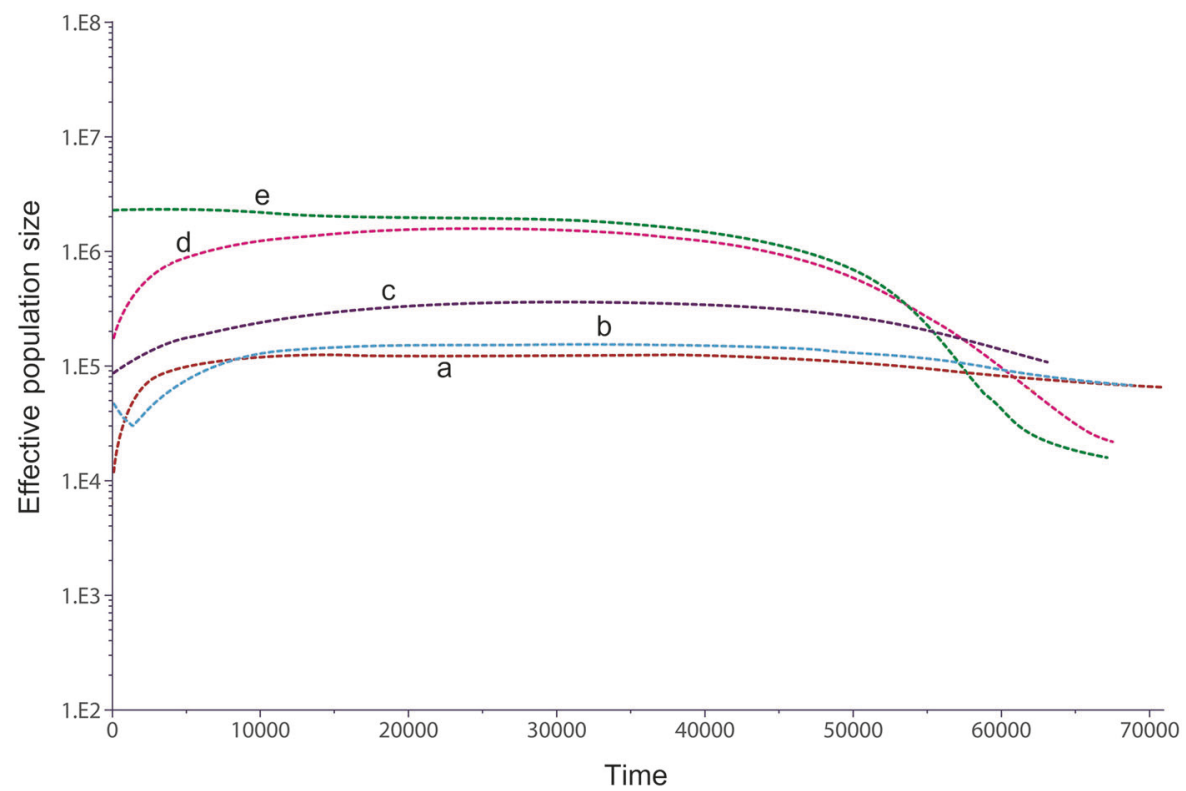

Figure S8). Linear Discriminate Analysis (LDA) plot shows that the observed data fall within the distributions simulated under the three models (Supplementary Figure S9) while the confusion matrix indicates some problems in distinguishing the continuous migration model from demic diffusion (Supplementary Table S4). This result is understandable, as the two scenarios only differ for the events of migration hypothesized between the AA and CT groups. However, the demic diffusion model had the highest posterior probability at 0.604 and was selected slightly more often among the classification trees $(0.515)$ than the continuous migration model (0.404); both of them were selected much more often than the cultural diffusion model (0.081) (Supplementary Table S5). Moreover, the estimated parameters for the continuous migration model indicate very low level of migration between CT and AA groups (Supplementary Table S6, Supplementary Figure S10). We conclude that demic diffusion, possibly with a very low level of gene flow between CT and AA groups, is the most likely scenario for the origins of central Thai populations.

\section{Genetic relationships of populations from different language families}

We also used the demographic modeling approach to test different models for the genetic relationships of populations belonging to the four main SEA language families (TK, AA, AN, and ST). In doing so, it is important to keep in mind that we are not testing the relationships of these language families, as that would require linguistic data. However, determining the best-fitting model based on genetic relationships may help discriminate among hypotheses concerning the language family relationships that make predictions about the genetic relationships of populations speaking those languages. We tested five models of the language family relationships (Fig. 3). The observed data fall within the range of the simulated data in the LDA plot (Supplementary Figure S9) while the confusion matrix confirms our ability to distinguish amongst the different scenarios (Supplementary Table S7). The model that best fit the mtDNA genome data was Model 1, according to Starosta [11] (Fig. 3a). The posterior probability of this model is 0.657 , and it was selected slightly more often among the classification trees (0.509) than Model 2 (0.311); the other models were much less often selected among the classification trees $(0.037$ for Model 3; 0.112 for Model 4; 0.031 for Model 5) (Supplementary Table S8). Because of the high selection frequency of Model 1 and Model 2, which have in common an ancestral relationship of TK and AN groups (Fig. 3a,b), we conclude that the TK and AN groups are descended from a common ancestral population.

\section{Discussion}

The present study adds to our previous study of Thai/Lao mtDNA genome sequences by including 22 additional groups from Thailand, including the AA-speaking Mon (MO), ST-speaking Karen, and several TK speaking groups, especially the CT. Similar to our previous mtDNA study [7], genetic heterogeneity among populations belonging to the same ethnic groups was still observed, especially for the Karen (the hill tribes) (Figs. 1, 4 and 5). Geographic isolation and matrilocal residence appear to be important factors influencing the genetic landscape of the highlanders. 
For the remaining lowland groups, i.e., Mon and other TKspeaking groups, gene flow with other groups is a rather more important factor.

The Mon, who were a previously dominant group in MSEA located in present-day southern Myanmar and central Thailand since the 6 to 7 th century A.D. [38], have been reported to link with Indian populations with some haplogroups, i.e., W3a1b [7]. With data from two additional Mon groups, there is still support for a connection between India and the Mon in the distribution of $\mathrm{M}$ subhaplogroups characteristic of South Asia or the Near East [39-41], e.g. M6a1a, M30, M40a1, M45a, and I1b (Supplementary Table S3). Genetic relationship analysis also reveals some Mon populations (MO1, MO5, MO6) clustering with Indian groups, although the other Mon groups were closely related to Thai/Lao populations (Supplementary Figure S5), possibly reflecting gene flow. Thus, based on the many older mtDNA lineages observed, the modern Mon from both Thailand and Myanmar could be an important group for further studies to reconstruct early SEA genetic history.

The Karen in Thailand are refugees who migrated from Myanmar starting from the 18th century A.D. due to the influence of Burmese [42]. However, the ancestors of the Karen probably migrated from some unknown location to Myanmar, as the Karen languages are thought to have originated somewhere in north Asia or in the Yellow River valley in China, i.e., the homeland of ST languages [43]. In agreement with previous studies of different Karen subgroups and/or different genetic markers [31, 44, 45], we find both northeast and southeast Asian components in the maternal ancestry of the Karen.

The present results emphasize the common maternal ancestry of CT and other TK speaking groups in MSEA, e.g., Laos and Southern China. Demic diffusion is still the most probable scenario for TK-speaking populations (Fig. 2a, Supplementary Table S5), possibly accompanied by some low level of gene flow with autochthonous Mon and Khmer groups. It seems that the prehistoric TK groups migrated from a homeland in south/southeast China to the area of present-day Thailand and Laos, and then split to occupy different regions of Thailand, expanding and developing their own history. During the migration and settlement period, genetic contact with the local AA people was certainly limited, but nonetheless the modeling results, haplogroup profiles and genetic diversity values all suggest some degree of admixture in the CT groups (Supplementary Table S3, Supplementary Table S6, Table 1). However, historical records indicate that large proportions of the CT groups were taken to neighboring kingdoms as war captives in multiple episodes from 500 to 300 ya [4]. The presentday CT people are probably not solely descended from the prehistorical TK groups, and admixture with local groups might have occurred starting from this time. However, in sum, cultural diffusion did not play a major role in the spread of TK languages in SEA.

Finally, we used simulations to test hypotheses concerning the genetic relationships of groups belonging to different language families. We found that Starosta's model [11] provided the best fit to the mtDNA data; however, Sagart's model $[9,10]$ was also highly supported. These two models both postulate a close linguistic affinity between TK and AN. Although genetic relatedness between TK and AN groups has been previously studied [7, 46, 47], to our knowledge this is the first study to use demographic simulations to select the best-fitting model. Our results support the genetic relatedness of TK and AN groups, which might reflect a postulated shared ancestry among the proto-Austronesian populations of coastal East Asia [48].

Specifically, the best-fitting model suggests that after separation of the prehistoric TK from AN stocks around 5-6 kya in Southeast China, the TK spread southward throughout MSEA around 1-2 kya by a demic diffusion process, accompanied by population growth but with at most minor admixture with the autochthonous AA groups. Meanwhile, the prehistorical AN ancestors entered Taiwan and dispersed southward throughout ISEA, with these two expansions later meeting in western ISEA. The lack of mtDNA haplogroups associated with the expansion out of Taiwan in our Thai/Lao samples has two possible explanations: either the Out of Taiwan expansion did not reach MSEA (at least, in the area of present-day Thailand and Laos); or, if the prehistoric AN migrated through this area, their mtDNA lineages do not survive in modern Thai/Lao populations. Ancient DNA studies in MSEA would further clarify this issue. Moreover, although mtDNA analyses are informative in elucidating genetic perspectives in geographically and linguistically related populations, they have an obvious limitation in that they only provide insights into the maternal history of populations. Future studies of $\mathrm{Y}$ chromosomal and genome-wide data will provide further insights into the genetic history of Thai/Lao populations and the role of factors such as post-marital residence patterns and migration in shaping the genetic structure of the region.

Acknowledgements We would like to acknowledge participants and coordinators, namely Supada Khonyoung, Dusit Boonmekam, Tharanat Hin-on, Kantaphon Chueahor, and Waraporn Hongsaphinan for assistance in collecting samples. We thank Prof. Murray Cox for his discussion and suggestions. This study was supported by the Max Planck Institute for Evolutionary Anthropology, the Thailand Research Fund (Grant No. MRG5980146), and Research and Academic Affairs Promotion Fund (RAAPF) of Faculty of Science, Khon Kaen University.

Author contributions WK and MS designed the study. WK, JK, MSr, $\mathrm{SR}, \mathrm{DK}$, and PP were involved in sample recruitment. WK, RS AH, $\mathrm{EM}$, and LA generated sequencing data. WK, SG, and AB analysed the data. WK, SG, AB AH, EM, LA, and MS wrote the manuscript with input from all other authors. 


\section{Compliance with ethical standards}

Conflict of interest The authors declare that they have no conflict of interest.

Open Access This article is licensed under a Creative Commons Attribution 4.0 International License, which permits use, sharing, adaptation, distribution and reproduction in any medium or format, as long as you give appropriate credit to the original author(s) and the source, provide a link to the Creative Commons license, and indicate if changes were made. The images or other third party material in this article are included in the article's Creative Commons license, unless indicated otherwise in a credit line to the material. If material is not included in the article's Creative Commons license and your intended use is not permitted by statutory regulation or exceeds the permitted use, you will need to obtain permission directly from the copyright holder. To view a copy of this license, visit http://creativecommons. org/licenses/by/4.0/

\section{References}

1. Simons GF, Fennig CD, editors. Ethnologue: Languages of the World. 20th edn. Texas, USA: SIL International; 2017. http:// www.ethnologue.com

2. Baker C, Phongpaichit P, editors. A history of Thailand. 2nd edn. Cambridge, UK: Cambridge University Press; 2009.

3. Revire N. Glimpses of Buddhist practices and rituals in Dvāravatī and its neighbouring cultures. In: Revire N, Murphy SA, editors. Before Siam, essay in art and archaeology. Bangkok, Thailand: River Books Co, Ltd; 2014. pp. 241-71.

4. Baker C, Phongpaichit P, editors. A history of Ayutthaya. Cambridge, UK: Cambridge University Press; 2017.

5. O'Connor R. Agricultural change and ethnic succession in Southeast Asian states: a case for regional anthropology. J Asian Stud. 1995;54:968-96.

6. Pittayaporn P. Layers of Chinese loanwords in proto-southwestern Tai as evidence for the dating of the spread of southwestern Tai. Manusya J Humanit. 2014;20:47-68.

7. Kutanan W, Kampuansai J, Srikummool M, et al. Complete mitochondrial genomes of Thai and Lao populations indicate an ancient origin of Austroasiatic groups and demic diffusion in the spread of Tai-Kadai languages. Hum Genet. 2017;136:85-98.

8. Peiros I, editor. Comparative linguistics in Southeast Asia. Canberra, Australia: Pacific Linguistics; 1998.

9. Sagart L. The higher phylogeny of Austronesian and the position of Tai-Kadai. Ocean Ling. 2004;43:411-44.

10. Sagart L. Sino-Tibetan-Austronesian: an updated and improved argument. In: Sagart L, Blench R, Sanchez-Mazas A, editors. The peopling of East Asia: Putting together archaeology, linguistics and genetics. London, UK: RoutledgeCurzon; 2005. pp. 161-76.

11. Starosta S. Proto-East Asian and the origin and dispersal of the languages of East and Southeast Asia and the Pacific. In: Sagart L, Blench R, Sanchez-Mazas A, editors. The peopling of East Asia: Putting together archaeology, linguistics and genetics. London, UK: RoutledgeCurzon; 2005. pp. 182-97.

12. Kampuansai J, Bertorelle G, Castri L, Nakbunlung S, Seielstad M, Kangwanpong D. Mitochondrial DNA variation of Tai speaking peoples in Northern Thailand. Sci Asia. 2007;33:443-8.

13. Lithanatudom $P$, Wipasa $J$, Inti $P$, et al. Hemoglobin $E$ prevalence among ethnic groups residing in malaria-endemic areas of Northern Thailand and its lack of association with plasmodium falciparum invasion in vitro. PLoS ONE. 2016;11:e0148079.
14. Meyer M, Kircher M. Illumina sequencing library preparation for highly multiplexed target capture and sequencing. Cold Spring Harb Protoc. 2010;6:1-10.

15. Maricic T, Whitten M, Pääbo S. Multiplexed DNA sequence capture of mitochondrial genomes using PCR products. PLoS ONE. 2010;5:e14004.

16. Arias-Alvis L, Barbieri C, Barreto G, Stoneking M, Pakendorf B. High Resolution Mitochondrial DNA analysis sheds light on human diversity, cultural interactions and population mobility in Northwestern Amazonia. Am J Phys Anthropol 2018; 165: 238-255.

17. Behar DM, van Oven M, Rosset S, et al. A "Copernican" reassessment of the human mitochondrial DNA tree from its root. Am J Hum Genet. 2012;90:675-84.

18. Katoh K, Standley DM. MAFFT multiple sequence alignment software version 7: improvements in performance and usability. Mol Biol Evol. 2013;30:772-80.

19. Kloss-Brandstätter A, Pacher D, Schönherr S, et al. HaploGrep: a fast and reliable algorithm for automatic classification of mitochondrial DNA haplogroups. Hum Mutat. 2010;32:25-32.

20. Fan L, Yao YG. MitoTool: a web server for the analysis and retrieval of human mitochondrial DNA sequence variations. Mitochondrion. 2011;11:351-6.

21. Excoffier L, Lischer HEL. Arlequin suite ver 3.5: a new series of programs to perform population genetics analyses under Linux and Windows. Mol Ecol Resour. 2010;10:564-7.

22. Jombart T, Ahmed I. Adegenet 1.3-1: new tools for the analysis of genome-wide SNP data. Bioinformatics. 2011;27:3070-1.

23. Bandelt HJ, Forster P, Röhl A. Median-joining networks for inferring intraspecific phylogenies. Mol Biol Evol. 1999;16:37-48.

24. Drummond AJ, Suchard MA, Xie D, Rambaut A. A Bayesian phylogenetics with BEAUti and the BEAST 1.7. Mol Biol Evol. 2012;29:1969-73.

25. Darriba D, Taboada GL, Doallo R, Posada D. jModelTest 2: more models, new heuristics and parallel computing. Nat Methods. 2012;9:772.

26. Soares P, Ermini L, Thomson N, et al. Correcting for purifying selection: an improved human mitochondrial molecular clock. Am J Hum Genet. 2009;84:740-59.

27. Pudlo P, Marin JM, Estoup A, Cornuet JM, Gautier M, Robert CP. Reliable $\mathrm{ABC}$ model choice via random forests. Bioinformatics. 2016;32:859-66.

28. Breiman L. Random forests. Mach Learn. 2001;45:5-32.

29. Derenko M, Malyarchuk B, Grzybowski T, et al. Origin and postglacial dispersal of mitochondrial DNA haplogroups C and D in Northern Asia. PLoS One. 2010;5:e15214.

30. Derenko M, Malyarchuk B, Bahmanimehr A, et al. Complete mitochondrial DNA diversity in Iranians. PLoS ONE. 2013;8: e80673.

31. Summerer M, Horst J, Erhart G, et al. Large-scale mitochondrial DNA analysis in Southeast Asia reveals evolutionary effects of cultural isolation in the multi-ethnic population of Myanmar. BMC Evol Biol. 2014;14:17.

32. Jinam TA, Hong LC, Phipps ME, et al. Evolutionary history of continental southeast Asians: "early train" hypothesis based on genetic analysis of mitochondrial and autosomal DNA data. Mol Biol Evol. 2012;29:3513-27.

33. Ko AMS, Chen CY, Fu Q, et al. Early Austronesians: into and out of Taiwan. Am J Hum Genet. 2014;94:426-36.

34. Peng MS, Quang HH, Dang KP, et al. Tracing the Austronesian footprint in mainland Southeast Asia: a perspective from mitochondrial DNA. Mol Biol Evol. 2010;27:2417-30.

35. Soares PA, Trejaut JA, Rito T, et al. Resolving the ancestry of Austronesian-speaking populations. Hum Genet. 2016;135:309-26. 
36. Duggan A, Evans B, Friedlaender FR, et al. Maternal history of Oceania from complete mtDNA genomes: contrasting ancient diversity with recent homogenization due to the Austronesian expansion. Am J Hum Genet. 2014;94:721-33.

37. Drummond AJ, Bouckaert RR, editors. Bayesian evolutionary analysis with BEAST. Cambridge, UK: Cambridge University Press; 2015.

38. Saraya D. (Sri) Davravati: The initial phrase of Siam's history. Bangkok, Thailand: Muang Boran Publishing House; 1999.

39. Chandrasekar A, Kumar S, Sreenath J, et al. Updating phylogeny of mitochondrial DNA macrohaplogroup M in India: dispersal of modern human in South Asian corridor. PLoS ONE. 2009;4: e7447.

40. Olivieri A, Pala M, Gandini F, et al. Mitogenomes from two uncommon haplogroups mark late glacial/postglacial expansions from the near east and neolithic dispersals within Europe. PLoS ONE. 2013;8:e70492.

41. Silva M, Oliveira M, Vieira D, et al. A genetic chronology for the Indian Subcontinent points to heavily sex-biased dispersals. BMC Evol Biol. 2017;17:88.

42. Grundy-Warr C, Huang S, Wong PP. Tropical geography: research and reflections. Singap J Trop Geogr. 2003;24:1-5.

43. LaPolla RJ. The role of migration and language contact in the development of the Sino-Tibatan language family. In: Aikhenvald
AY, Dixon RMW, editors. Areal diffusion and generic inheritance: Problems in comparative linguistics. Oxford, UK: Oxford University Press; 2001. pp. 225-54.

44. Listman JB, Malison RT, Sanichwankul K, Ittiwut C, Mutirangura A, Gelernter J. Southeast Asian origins of five hill tribe populations and correlation of genetic to linguistic relationships inferred with genome-wide SNP data. Am J Phys Anthopol. 2011;144:300-8.

45. Kutanan W, Srikummool M, Pittayaporn P, et al. Admixed origin of the Kayah (Red Karen) in Northern Thailand Revealed by Biparental and Paternal Markers. Ann Hum Genet. 2015;7:108-22.

46. Dancause KN, Chan CW, Arunotai NH, Lum JK. Origins of the Moken Sea Gypsies inferred from mitochondrial hypervariable region and whole genome sequences. J Hum Genet. 2009;54:86-93.

47. Mirabal S, Cadenas AM, Garcia-Bertrand R, Herrera RJ. Ascertaining the role of Taiwan as a source for the Austronesian expansion. Am J Phys Anthropol. 2013;150:551-64.

48. Bellwood P. Austronesian prehistory in Southeast Asia: homeland, expansion and transformation. In: Bellwood P, Fox JJ, Tryon $\mathrm{D}$, editors. The Austronesians: historical and comparative perspectives. Canberra, Australia: ANU E Press; 2006. pp. 103-14. 